\title{
Author Spotlight: Matthew S. Sussman
}

\section{Matthew S. Sussman ${ }^{1}$}

Published online: 18 June 2020

(c) Springer Science+Business Media, LLC, part of Springer Nature 2020

Matthew S. Sussman, MD, is a third year general surgery resident at the University of Miami/Jackson Memorial hospital. He completed his MD at Florida International University. Matthew is currently completing a two-year research fellowship at the Ryder Trauma Center. His research focuses on trauma clinical outcomes and resident education. Over the course of his fellowship has also worked closely with the Army Trauma Training Detachment at the Ryder Trauma Center preparing forward surgical teams for downrange surgical resuscitation. Matthew is also currently enrolled in a dual accredited MBA in healthcare management and policy. He has teamed up with data scientist to create an artificial intelligence platform that autonomously aggregates pricing and quality information on healthcare services to suggest optimal products to patients based on their personal health insurance and demographic information. He hopes to pursue a career in vascular surgery.

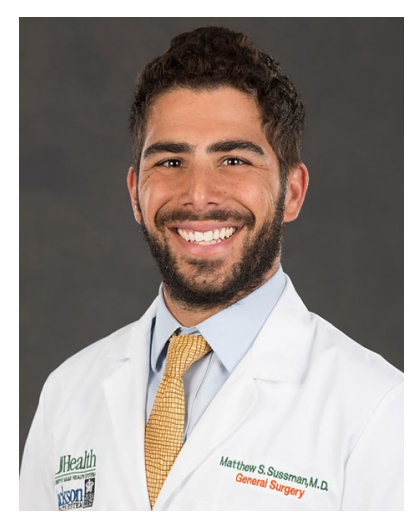

Publisher's Note Springer Nature remains neutral with regard to jurisdictional claims in published maps and institutional affiliations.
Matthew S. Sussman

matthew.sussman@jhsmiami.org

1 DeWitt Daughtry Family Department of Surgery, University of Miami, Miami, USA 